Part of Journal of Research of the National Bureau of Standards, Volume 19, October 1937

\title{
ELECTRICAL CHARACTER OF THE SPARK DISCHARGE OF AUTOMOTIVE IGNITION SYSTEMS
}

\author{
By Melville F. Peters, George F. Blackburn, and Paul T. Hannen
}

\section{ABSTRACT}

To determine the character of a spark discharge it is necessary to determine current and voltage as functions of time. The measurement of these quantities is facilitated by the use of the cathode ray oscillograph, but due consideration must be given to the effect of the measuring circuit, including connections to the oscillograph, on the character of the discharge, especially in investigations of automotive ignition circuits.

Two methods suitable for measuring the current in the discharge with the cathode ray oscillograph are (1) measurement of the voltage across a known inductance, and (2) deflection of the cathode beam by the magnetic field set up by the current. The paper deals in detail with the application of these two methods, including, in the first method, the equations by which the current is derived, and the method of calibrating the measuring circuit in both methods.

An analysis is made of oscillograms obtained by both methods for the discharge in the calibrating circuits and in a typical ignition circuit. Crest currents of 50 to $80 \mathrm{amp}$ were measured. The frequencies ranged from 6 to $10 \mathrm{Mc} / \mathrm{s}$, the decrements from 0.08 to 0.40 , and the energy expended from 0.0023 to $0.0135 \mathrm{j}$. The expended energy is found to agree with the energy known to be stored in the capacitance of the circuit at the beginning of the discharge.

I. Introduction . . . . .

II. Description of methods of current measurement_........... 402

1. Measurement of voltage across a known resistance _._. . . . 402

2. Measurement of voltage across a known inductance $\ldots . . . . . .403$

3. Measurement of magnetic deflection _... . . _.......... 404

III. Description of apparatus _. 405

IV. Experimental procedure _.

1. Determination of inductance of standard inductors _....... 406

(a) Computation $\ldots$

(b) Measurement

2. Calibration of oscillograph

(a) Measurement of voltage across standard inductors... 407

(b) Measurement of current by magnetic defiection....... 408

V. Determination of electrical characteristics from the oscillograms...... 409

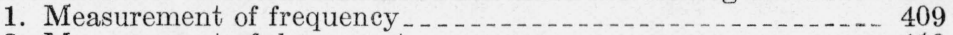

2. Measurement of decrement

3. Evaluation of resistance $\ldots$

4. Evaluation of energy _...... 411

VI. Results _............. 411

1. Spark characteristics by measurement of voltage across a

known inductance.......... 411

(a) Calibration . . .

(b) Measurements on typical ignition circuit......... 413

2. Spark characteristics by measurement of magnetic deflection.- 414

(a) Measurements on typical ignition circuit_......... 414

(b) Calibration . .

VII. Discussion of results _____ 417

VIII. References _

Appendix A. Derivation of expression for voltage across capacitance of oscillograph circuit_.......... 418

Appendix B. Displacement of line of zero voltage on an oscillogram 


\section{INTRODUCTION}

The electrical character of a spark discharge may be determined if both current and voltage are known as functions of time. When these have been determined such quantities as crest voltage, crest current, frequency, decrement, and energy may be deduced. For the measurement of voltage and current the most suitable instrument is the cathode ray oscillograph. In making these measurements it is necessary to introduce apparatus into the discharge circuit which unavoidably changes the effective resistance, inductance, and capacitance of the circuit. If the electrical constants of the discharge circuit are large, as compared to those of the measuring apparatus, care must be taken in selecting the apparatus so that either the nature of the circuit is not seriously affected or correction may be made for the change in the character of the discharge.

In automotive ignition systems the capacitances of the individual leads from the spark coil or magneto to and including the spark plugs have been found to lie between 40 and $300 \mu \mu f$. The inductances of the corresponding leads lie between 0.5 and $3 \mu \mathrm{h}$. The direct-current resistance of the leads is small.

A technique for measuring voltage across a spark-plug gap, using a low-capacitance voltage divider with the cathode-ray oscillograph, has been described by the authors [1] ${ }^{1}$. Such additional considerations as are necessary will be taken up in appendix B.

The present paper considers three methods of measuring the discharge current using the cathode-ray oscillograph, viz: (1) By measing the voltage drop across a resistance; (2) by measuring the voltage drop across an inductance, and (3) by deflecting the cathode beam magnetically by means of coils introduced into the circuit. The principles underlying these three methods are well known, but the magnitudes of the electrical constants of an automotive ignition circuit impose limitations upon their application to such circuits. One of the primary objects of this work is to develop technique which can be used to determine the character of spark discharges of automotive ignition systems without appreciably disturbing the ignition circuit.

This work was sponsored by the Bureau of Aeronautics of the U. S. Navy Department and was completed in April 1933.

\section{DESCRIPTION OF METHODS OF CURRENT MEASUREMENT}

\section{MEASUREMENT OF VOLTAGE ACROSS A KNOWN RESISTANCE}

The Dufour or cold cathode type of oscillograph is well suited to the observation and measurement of spark-discharge phenomena, because of the high-speed transients involved. Since the voltage sensitivity of this type of oscillograph is only about $0.004-\mathrm{cm}$ deflection of the cathode beam per volt, a convenient deflection requires the application of several hundred volts. Assuming a crest discharge current of $50 \mathrm{amp}$, a resistance of $5 \mathrm{ohms}$ would have to be inserted in the discharge circuit to produce a deflection of $1 \mathrm{~cm}$. Since the effective resistance of the circuit during discharge, as determined from the decrement, is of the same order of magnitude as this, it is evident

\footnotetext{
${ }^{1}$ Figures in brackets here and throughout the text refer to the references given in sec. VIII, p. 418.
} 
that the addition of the required resistance would produce a considerable change in the decrement of such a circuit.

A resistance of $0.1 \mathrm{ohm}$ or less could be used if the voltage across the resistance were amplified. An objection to this procedure is that it is difficult to find a resistor which has negligible inductance. At high frequencies the presence of inductance in the resistor results in an inductive voltage component in the deflection, which may be greater than that due to the resistance. In the course of experiments with a specially built amplifier and so-called noninductive resistors this was found to be true and suggested the advisability of measuring peak current by measuring the voltage drop across a known inductance.

\section{MEASUREMENT OF VOLTAGE ACROSS A KNOWN INDUCTANCE}

When a capacitance $C$ discharges through an inductance $L$ and resistance $R$, the current at time $t$ after the beginning of the discharge may be given by

$$
i=\frac{V_{0}}{\omega L} e^{-\alpha t} \sin \omega t
$$

if $\alpha^{2}<1 / C L$. Here $\alpha=R / 2 L, \omega=\sqrt{1 / C L-R^{2} / 4 L^{2}}$, and $\mathrm{V}_{0}$ is the voltage of the capacitor at the beginning of the discharge.

The potential difference across a part $L_{1}$ of the inductance at a time $t$ is given by

$$
v_{L_{1}}=\frac{V_{0} L_{1}}{\omega L} \sqrt{\alpha^{2}+\omega^{2}} e^{-\alpha t} \cos (\omega t+\theta),
$$

where $\theta=\tan ^{-1} \alpha / \omega$

From eq 1 and eq 2 the relation between a voltage crest and the current crest which follows the voltage crest by approximately onequarter cycle is

$$
I=\frac{V}{L_{1} \sqrt{\alpha^{2}+\omega^{2}}} e^{\left[\frac{a}{\omega}\left(\frac{\pi}{2}+\theta\right)\right]}
$$

If $\alpha=0$ this reduces to the relation between maximum voltage and current in an undamped sine wave,

$$
I=\frac{V}{\omega L_{1}}
$$

In a spark discharge in an ignition circuit $\alpha$ is usually very small compared with $\omega$, so that in computing the crest current from eq 4 the error introduced by neglecting the damping factor is less than the error resulting from experimental errors in measuring $V, \omega$, and $L_{1}$.

To apply this method of current measurement, a single-layer coil is constructed whose inductance can be measured or readily computed. The magnitude of the inductance must be such that the characteristics of the discharge are not affected to any considerable extent by its inclusion in the circuit, and that a convenient deflection on the oscillograph is produced by the discharge. The high-frequency resistance of the coil can be made negligibly small in comparison with its inductance, and the self-capacitance can also be made negligibly small. The quantities $V$ and $\omega$ are obtained from oscillograms. 
Figure 1 shows diagrammatically the arrangement used for measuring the potential difference across $L_{1}$. The capacitance $C^{\prime}$ represents that of the oscillograph plates and of the voltage divider, if one is used. The resistance and inductance of the connecting wires are represented by $R^{\prime}$ and $L^{\prime}$, respectively. In order to reduce the effect of the measuring circuit on the discharge circuit, $C^{\prime}$ should be small compared to $C$.

Assuming that the influence of the measuring circuit on the discharge circuit is negligible, it is next necessary to determine the effect of the electrical constants of the connecting leads on the pattern obtained in the oscillograph. In order to do this a damped high-frequency voltage whose maximum value is known is applied to the terminals of the inductance $L_{1}$ and the oscillograph deflection compared with the deflection due to the same voltage at low frequency. This serves to determine what correction, if any, must be applied to the current values obtained from the deflections measured on an oscillogram to obtain the true current in the discharge circuit. The maximum value, frequency, and damping of the current used for this calibration are made as nearly as practicable like those of the current in the ignition

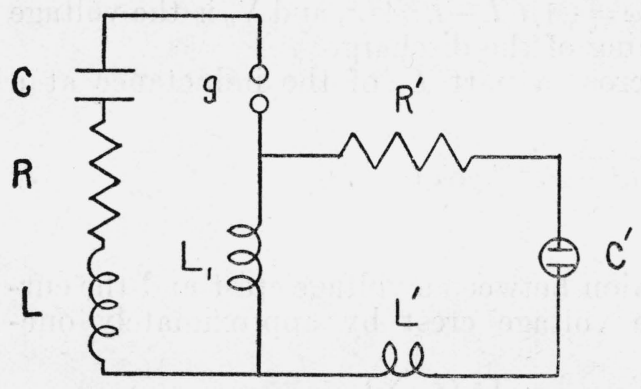

Figure 1.-Schematic diagram of circuit used in measuring voltage across inductance. circuit to be studied, and it is then assumed that the same correction factor is valid for both circuits.

A detailed analysis of the relation between the voltage across the deffection plates and the voltage across the inductance $L_{1}$ will be found in appendix A, page 418. This analysis shows the correction to be applied in terms of the constants of both circuits.

The manner of determining experimentally the correction factor will be described in section IV, page 407 .

\section{MEASUREMENT OF MAGNETIC DEFLECTION}

In this method the cathode beam of the oscillograph is deflected by the magnetic field which is created when the discharge current flows through two coils placed adjacent to the beam, and with their common axis normal to its path. The deflection is proportional to the strength of field, and hence to the current, and takes place at right angles both to the direction of the field and that of the beam. For a given current the strength of field along the path traversed by the beam depends on the dimensions and location of the coils. The coils, which are symmetrically placed on opposite sides of the path of the beam, are connected in parallel in order to avoid setting up an electrostatic field.

To obtain a convenient deflection as the experimental conditions are changed requires a change either in the dimensions of the coils, or their positions, or both. With each change, a calibration is necessary to obtain the sensitivity in centimeters deflection per ampere.

This method is applicable to current of any wave form, or to nonoscillating current. 


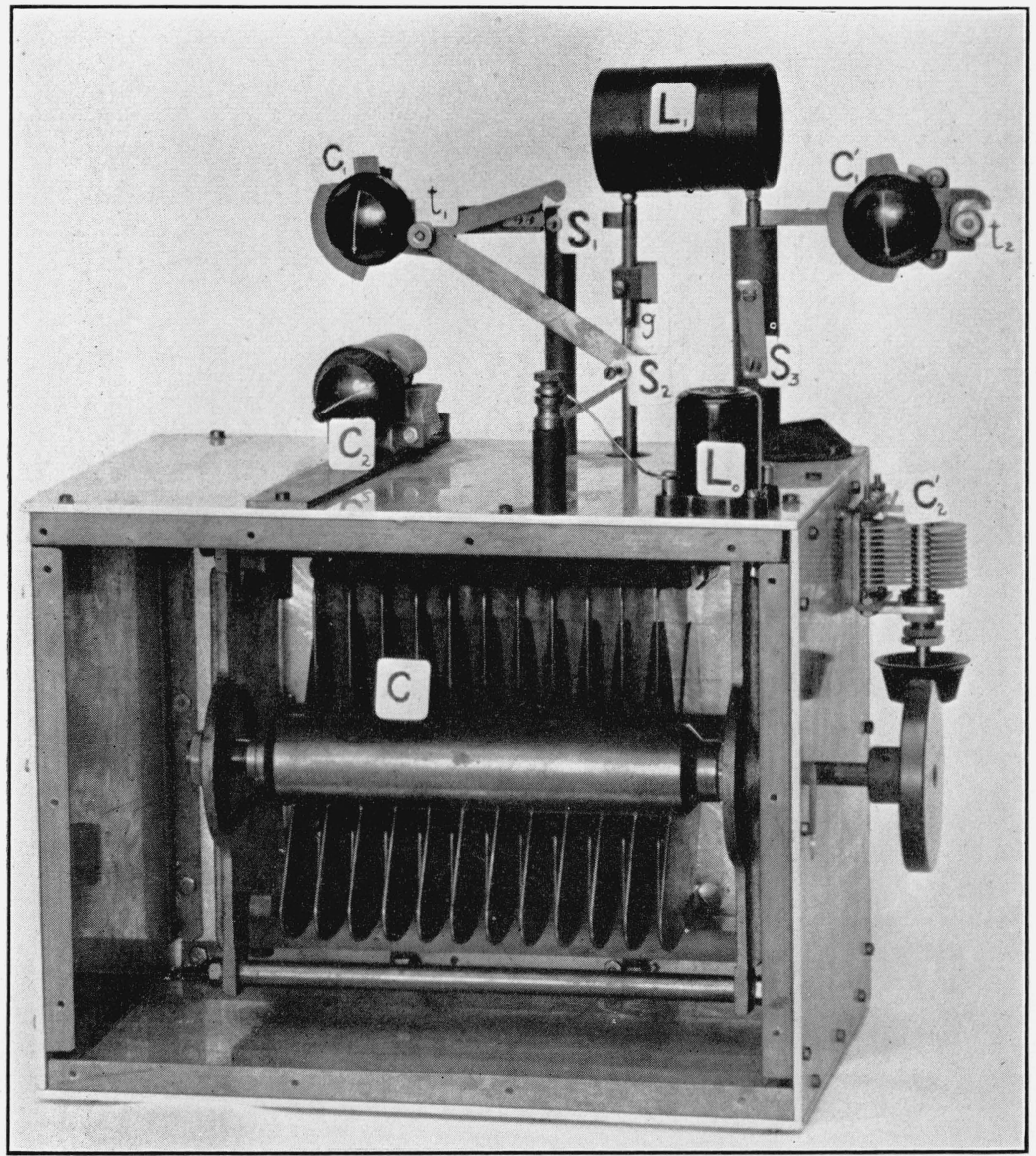

FigURE 2.-Arrangement used to supply heavy current discharges for calibrating the oscillograph.

$C$, High-voltage variable air capacitor; $L_{0}$, choke coil; $L_{1}$, standard inductor; $g$, spark gap; $C_{1}, \mathrm{C}_{1}^{\prime}, C_{2}$. $C_{2}^{\prime}$, variable air capacitors; $s_{1}, s_{2}, s_{3}$, switches; $t_{1}, t_{2}$, terminals. 


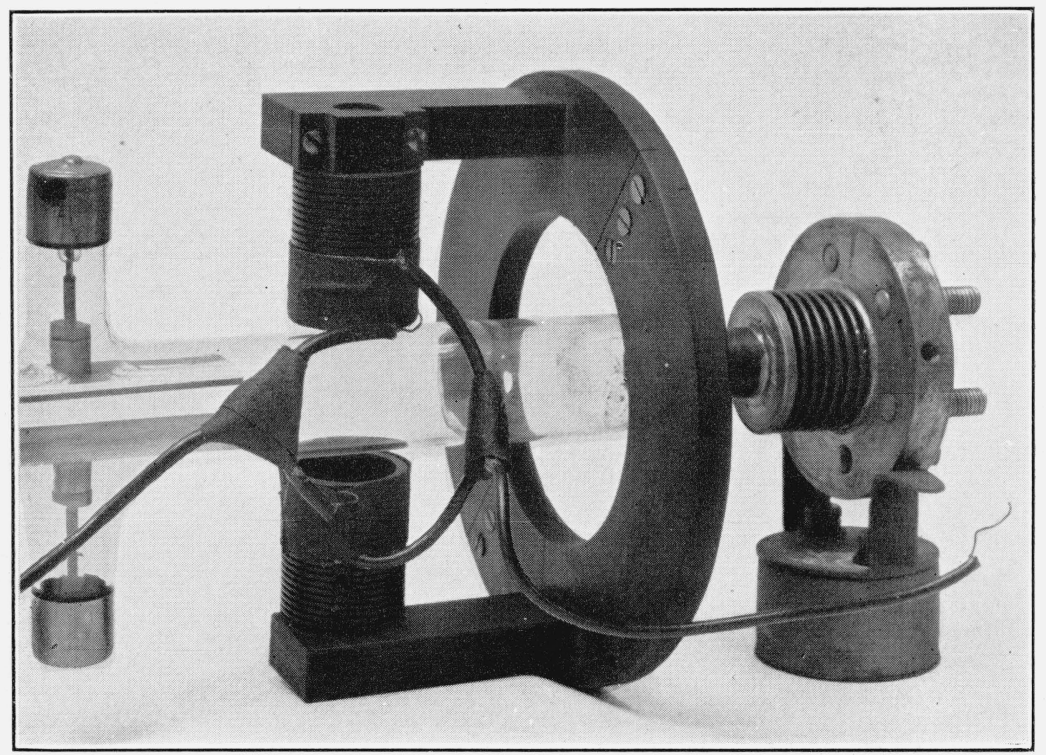

FIGURE 4.-Deflecting coils as supported in their positions adjacent to the deflection tube. 


\section{DESCRIPTION OF APPARATUS}

The cathode ray oscillograph was of the high-voltage cold-cathode type. The cathode was operated at approximately $60,000 \mathrm{v}$, the supply being the secondary of a transformer. The primary was connected to a $60-\mathrm{c} 110 \mathrm{-v}$ supply through rotary switches operated by a synchronous motor driven from the same source. The switches were constructed so that the negative voltage was applied to the cathode during one half cycle, once in every 100 cycles.

Figure 2 is a photograph and figure 3 a diagram of the standard circuit used to supply heavy-current spark discharges at high frequencies. The capacitor $C$ is in the metal box and has a range of 50 to $300 \mu \mu \mathrm{f}$. The rotating plates of the capacitor are permanently connected to an aluminum shielding box, and the assembly was calibrated for capacitance. The spark gap is at $g$, and interchangeable inductors are inserted in the circuit at $L_{1} . \quad L_{0}$ is a $60-\mathrm{mh}$ choke coil to prevent oscillations from the magneto circuit affecting the standard

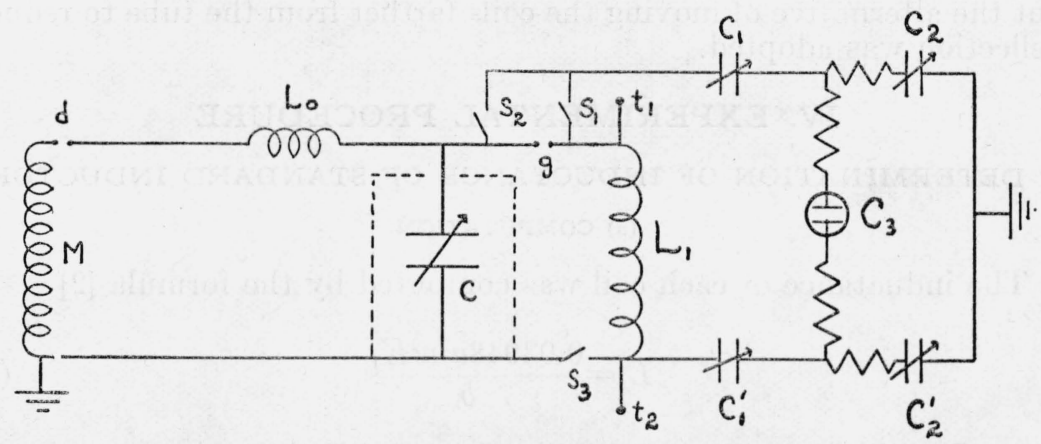

Figure 3.-Diagram of circuit used to calibrate the oscillograph.

circuit during the high-frequency discharge. The distributor gap of the magneto $M$ is shown at $d$. The voltage divider consists of four capacitors: $C_{1}, C_{1}{ }^{\prime}$, each having a maximum capacitance of $15 \mu \mu \mathrm{f}$, and $C_{2}, C_{2}{ }^{\prime}$, each having a maximum capacitance of $100 \mu \mu \mathrm{f}$.

Provision is made at $s_{1}$ for connecting $C_{1}$ to the inductance coil $L_{1}$, and at $s_{2}$ to the high-voltage side of the spark gap. The latter connection is made for calibrating, since it is desired to compare in a single spark discharge the breakdown voltage of the gap with the crest voltage across the inductance coil. After being calibrated the measuring circuit with terminals $t_{1}$ and $t_{2}$ is connected in series with the circuit under investigation.

At $s_{3}$ is a switch used to open or close the circuit from the coil to the shielding box, which is grounded. When coil $L_{1}$ is connected in the circuit being studied, $s_{1}$ connects $C_{1}$ to the circuit, and $s_{2}$ and $s_{3}$ are opened.

Balancing of the capacitance voltage divider has been described by the authors [1]. Briefly, the divider is balanced by applying a high voltage, such as that generated by the magneto, to both sides of the divider. To accomplish this, $s_{1}$ and $s_{2}$ are closed and $s_{3}$ is opened slightly, so that it acts as a spark gap. If the divider is balanced the cathode beam is not deflected during the charging or the discharge 
of the spark gap $s_{3}$. If the beam is deflected the divider may be balanced and the deflection reduced to zero by changing the capacitance of $C_{1}$ or $C_{2}$.

The calibration was made first with an inductance coil, $L_{1}, 5.2 \mathrm{~cm}$ long and $5.1 \mathrm{~cm}$ in diameter wound with three turns of copper wire $0.07 \mathrm{~cm}$ in diameter, and then with a second coil $5.2 \mathrm{~cm}$ long, $5.1 \mathrm{~cm}$ in diameter wound with five turns of copper wire $0.07 \mathrm{~cm}$ in diameter.

Figure 4 shows how the magnetic deflection coils were placed in their supports adjacent to the deflection tube. A special tube was made to permit the use of these coils. The regular tube has two pairs of deflection plates, one pair horizontal and the other pair vertical. The special tube has the horizontal plates, but the vertical plates are omitted to prevent the shielding of the electron beam from the magnetic field by the eddy currents which would have been induced in the vertical plates by the magnetic field.

Sufficient deflection was produced under the prevailing conditions, with three turns of wire on each coil. Often less could have been used, but the alternative of moving the coils farther from the tube to reduce deflection was adopted.

\section{EXPERIMENTAL PROCEDURE}

\section{DETERMINATION OF INDUCTANCE OF STANDARD INDUCTORS}

(a) COMPUTATION

The inductance of each coil was computed by the formula [2]

$$
L_{s}=\frac{0.03948 a^{2} n^{2} K}{b}
$$

where $a$ is the radius of the coil, $b$ is its length, $n$ is the number of turns, and $K$ is a factor which depends on the ratio of the diameter to the length. $L_{s}$ is the inductance in microhenries of the current sheet of the given dimensions, and a correction must be made to take into account the size and shape of the cross section of the wire. The corrected value of the inductance is given by

$$
L_{0}=L_{s}-0.01257 a n(A+B) \text {, }
$$

in which $L_{\mathrm{o}}$ is the inductance of the coil at low frequencies, $A$ is a constant which takes into account the difference in self-inductance of a turn of wire from that of a current sheet, and $B$ depends on the difference in mutual inductance of the turns of the coil from that of the turns of the current sheet. $A$ is given as a function of the ratio of the diameter of the wire to the distance between centers of the wire measured along the axis, and $B$ is a function of the number of turns.

The ratio of diameter to length of both coils was 1.02. For this ratio the factor $K$ is 0.6884 . For the three-turn coil the value of $A$ is -2.640 and the value of $B$ is +0.166 . For the five-turn coil $A$ is -2.144 and $B$ is +0.218 .

Substituting these values and the dimensions of the coils in equations 5 and 6 , the resulting values of low-frequency inductance are $0.54 \mu \mathrm{h}$ for the three-turn coil and $1.15 \mu \mathrm{h}$ for the five-turn coil. 
(b) MEASUREMENT

In order to check experimentally the computed inductance of the two coils, the total inductance of the standard discharge circuit, which includes the inductance of the coil and connecting circuit, was determined by the following method [2]. With the spark-gap electrodes in contact and the inductance loosely coupled to a variablefrequency oscillator, the calibrated variable capacitor $C$ of the standard circuit was given various settings, and for each setting the natural frequency of the circuit was found, indicated by resonance with the oscillator. Since $1 / \omega^{2}=L\left(C+C_{0}\right)$, where $\left(C+C_{0}\right)$ is the total capacitance and $L$ is the total inductance of the discharge circuit at high frequency, the plot $1 / \omega^{2}$ versus $C$ is linear. The slope of this line gives the inductance $L$, and the intercept on the $C$ axis gives $C_{0}$.

With the three-turn coil the total inductance of the circuit was found to be $0.67 \mu \mathrm{h}$, and with the five-turn coil $1.27 \mu \mathrm{h}$. The difference between the experimentally determined inductance for the circuit and the computed value for the coil should equal the inductance of the connecting circuit. For the three-turn coil this difference is $0.12 \mu \mathrm{h}$ and for the five-turn coil it is $0.11 \mu \mathrm{h}$. The closeness of this agreement serves as an experimental check on the calculated values of the inductances of the coils.

\section{CALIBRATION OF OSCILLOGRAPH}

(a) MEASUREMENT OF VOLTAGE ACROSS STANDARD INDUCTORS

As was shown in section II, it is necessary to find what correction, if any, must be applied to the voltage recorded by the oscillograph to obtain the true voltage across the standard inductors. This constitutes a calibration of the oscillograph and is done in the following manner.

The standard discharge circuit is used, with $C$ set at the desired value and with one of the standard inductors $L_{1}$ in the circuit. Referring to figure 3 , switch $s_{1}$ is open, $s_{2}$ and $s_{3}$ are closed. Thus the charging voltage applied to the capacitor $C$, to break down the gap $g$, is applied also to the oscillograph circuit, comprising the capacitors of the capacitance voltage divider, the inductance and resistance of the connecting wires, and any resistors that have been added to prevent the occurrence of parasitic oscillations in the oscillograph circuit. This charging voltage builds up at a relatively slow rate, and the voltage recorded by the oscillograph is then related to this charging voltage by a factor $K$ which depends only on the settings of the capacitors of the voltage divider.

One method of determining the factor $K$ consists in applying an alternating voltage of about $1,000 \mathrm{v}$ at a frequency of several thousand cycles per second to one pair of deflecting plates and to the voltage divider, which is connected to the other pair. The slope of the resulting straight line on an oscillogram is a measure of the factor $K$.

Upon the breakdown of the gap $g$, the capacitor $C$ discharges through the inductance and resistance of the circuit, usually in an oscillatory manner, and the oscillograph records the oscillations of voltage, and their decreasing amplitude. Any correction which is required because of the effect of the measuring circuit on the record obtained on an oscillogram is determined by comparing the deflection due to the gap breakdown voltage with the maximum deflection on the succeeding 
cycle, after multiplying this maximum deflection by a factor to correct for the decay of voltage from one cycle to the next. In arriving thus at the correction factor, it is assumed, first, that no sensible error is introduced by regarding the inductance between the points of oscillograph connection to the discharge circuit as the total inductance of the discharge circuit; second, that the effect of the resistance of the circuit may be neglected in comparison with the inductance; and third, that the damping factor has approximately the same value for the first cycle as it does during the cycles immediately following the first. It has been found that the error arising by reason of these assumptions is less than the experimental error of measurement of the deflection on an oscillogram, which is usually 3 percent or more.

(b) MEASUREMENT OF CURRENT BY MAGNETIC DEFLECTION

Calibration of the oscillograph for this method of current measurement consists in determining the current sensitivity of the oscillograph,

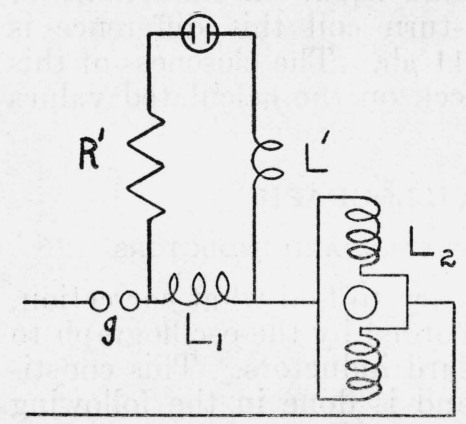

FIgURE 5.-Schematic diagram of circuit used to calibrate the oscillograph for measurement of current by magnetic deflection. and is most conveniently carried out after a suitable oscillogram has been obtained of the current in the ignition circuit under test. With this procedure the deflection coils are placed adjacent to the deflection tube so as to give a convenient deflection by the current in the ignition circuit, and the coils are not disturbed during the calibration.

The calibration was carried out with high-frequency discharge current. The procedure for calibrating consists in modifying the circuit of figure 1 by putting the deflection coils $L_{2}$ in series with the inductor $L_{1}$ (fig. 5). Then one or more oscillograms are made of the deflection due to the discharge current in the standard circuit flowing in $L_{2}$, with the deflection plates disconnected from $L_{1}$. Besides the deflection, the frequency of the discharge also is obtained from this oscillogram. The deflection coils are then removed from the deflection tube to a distance such that their field cannot affect the cathode beam and the deflection plates connected to $L_{1}$. This arrangement gives oscillograms of the crest voltage across $L_{1}$ due to the discharge current, and from this deflection and the frequency the crest current is obtained, as in the method first described. Assuming that the crest currents in the discharges observed in these two ways are of equal value, the sensitivity of the oscillograph in centimeters deflection per ampere is deduced.

Since it is known that the breakdown voltage of the gap may be different for separate discharges, it is desirable to take the average of a number of oscillograms of each type. The ideal method would be to record the crest voltage across $L_{1}$ and the crest current through $L_{2}$ on the same discharge. However, the quadrature of phase between current and voltage causes the cathode beam to describe a spiral path, and it was found that at high frequencies the linear velocity of the beam across the photographic film at the outside of this spiral was too high to leave a well-defined trace, while toward the center considerable 
fogging resulted from the action of the cathode beam at one spot prior to the discharge. At the time this work was done these difficulties had not been overcome, so that the method first described was considered preferable.

Subsequent experiments with a discharge circuit having a natural frequency of $5.0 \mathrm{Mc} / \mathrm{s}$ have shown that oscillograms of simultaneous current and voltage can be obtained by limiting the maximum deflection along both axes to a moderate amount and by sweeping the cathode beam across the film horizontally at a moderate rate, so as to avoid undue fogging of the film by the protracted presence of the cathode beam. The discharge is timed to occur while the beam is crossing the film. In this instance the sweep speed was about $10^{4}$ $\mathrm{cm} / \mathrm{sec}$, and the film width was traversed in about $1.3 \times 10^{-3}$ sec. Since the duration of the discharge was about $10^{-6} \mathrm{sec}$ the displacement of the beam due to the sweep speed during the period of the discharge was only about $10^{-2} \mathrm{~cm}$. The maximum deflection from the origin was $3 \mathrm{~cm}$.

At this frequency it was found that the current sensitivity, about $0.03 \mathrm{~cm}$ deflection per ampere, was the same as for direct current.

\section{DETERMINATION OF ELECTRICAL CHARACTERISTICS FROM THE OSCILLOGRAMS}

If oscillograms have been obtained by either of the two methods of current measurement, it is possible to derive various quantities which are characteristic of or associated with the circuit producing the discharge. These will now be considered.

\section{MEASUREMENT OF FREQUENCY}

Since it is desired to know the voltage and current as functions of time, it is necessary to sweep the beam across the photographic film at a known rate of speed. This speed must be such that the deflections due to voltage or current, which are caused to take place at right angles to the direction of the time axis, are clearly delineated. This was accomplished by using a high-voltage oscillator to deflect the beam in a vertical direction across the film, at a frequency of $77.5 \mathrm{kc} / \mathrm{s}$. This produced the time axis. Since the output voltage $E$ at a time $t$ is $E=E_{\max } \sin 2 \pi F t$, where $F$ is the sweep frequency in cycles per second, the motion of the beam across the film is given by $d=D \sin 2 \pi F t$, where $D$ is the amplitude and $d$ is the deflection at time $t, t$ being referred to the epoch $t_{0}$ when $d=0$. Thus, since $t=\left(1 / 2 \pi F^{\prime}\right)$ $\left(\sin ^{-1} d / D\right)$, the time interval between any two points is given by

$$
t_{2}-t_{1}=\frac{1}{2 \pi F}\left(\sin ^{-1} \frac{d_{2}}{D}-\sin ^{-1} \frac{d_{1}}{D}\right) .
$$

This expression is valid only if $t_{1}$ and $t_{2}$ refer to the time at the beginning of the quarter-cycle $(d=0)$ in which $d_{1}$ and $d_{2}$ occur. If $d_{1}$ and $d_{2}$ lie on opposite sides of the point $d=0$, the terms within parentheses must be added.

The position of the time axis being vertical, the voltage or current to be measured is applied so as to produce a horizontal deflection and the oscillations whose frequency is to be measured are then spread out along the time axis. A convenient number $n$ of these 
oscillations is chosen, and the time interval $\left(t_{2}-t_{1}\right)$ between these cycles measured. The frequency is then

$$
f=\frac{n}{t_{2}-t_{1}}=\frac{2 \pi F n}{\sin ^{-1} \frac{d_{2}}{D}-\sin ^{-1} \frac{d_{1}}{D}}
$$

\section{MEASUREMENT OF DECREMENT}

The decrement of a damped alternating current is usually defined as the natural logarithm of the ratio of a current maximum to the next current maximum in the same direction.

$$
\delta_{n}=\log \frac{I_{n}}{I_{n+1}}
$$

If $v$ is the potential difference produced by this damped current, then

$$
\delta_{n}=\log \frac{V_{n}}{V_{n+1}}
$$

By evaluating $V_{n}$ and $V_{n+1}$ from eq 2 , the decrement is found to be

$$
\delta_{n}=\frac{2 \pi \alpha_{n}}{\omega}=\frac{\pi R_{n}}{\omega L}
$$

since $\alpha_{n}=R_{n} / 2 L$.

When $R$, which is the total resistance in the circuit, is constant, the damping is logarithmic. When $R$ varies in such a way that the oscillations diminish in amplitude by a constant difference, the damping is linear. The actual damping in ignition circuits is usually found to lie between these two extremes. The decrement may also be measured by measuring the double amplitude, which is sometimes more easily done than measuring the amplitude. That is, if $I_{n}{ }^{\prime}$ is the maximum current in the opposite direction following $I_{n}$, and $I^{\prime}{ }_{n+1}$ is the maximum current following $I_{n+1}$, then

$$
\delta_{n}=\log \frac{I_{n}+I_{n}^{\prime}}{I_{n+1}+I_{n}^{\prime}+1}
$$

Another relation that is sometimes useful is

$$
\frac{I_{n}}{I_{n}{ }^{\prime}}=\left[\frac{I_{n}+I_{n}{ }^{\prime}}{I_{n+1}+I_{n}{ }^{\prime}+1}\right]^{\frac{1}{2}}
$$

although it is strictly true only if the damping is logarithmic.

\section{EVALUATION OF RESISTANCE}

Equation 10 can be written

$$
R_{n}=\frac{\omega L \delta_{n}}{\pi}
$$

If $\omega^{2}=1 / L C$, which is nearly true if $R_{n}^{2}$ is small in comparison with $4 L / C$, then $R_{n}$ is given by

$$
R_{n}=\frac{\delta_{n}}{\pi \omega C}
$$


in which the capacitance $C$ measured at low frequency is taken as the capacitance at the discharge frequency.

The effective resistance $R$ has three components, namely, gap resistance, circuit resistance, and radiation resistance. In the case of a shielded ignition harness, the radiation is very small and the radiation resistance probably negligible. In such a circuit, the distributed nature of the capacitance and inductance makes it difficult to calculate the high-frequency resistance. For these reasons no attempt has been made to separate the losses in the gap from those in the rest of the circuit.

The fact that in the discharge in an ignition circuit $\delta$ is not constant indicates that $R$ is not constant. The variation in $R$ is due to the variation in the gap resistance. The gap resistance probably varies in some manner with the instantaneous current in the gap, but the value of $R$ given by eq 13 is the effective value of the total resistance of the circuit, and is assumed to be the effective resistance during any cycle in which the decrement is $\delta$. With ignition circuits this effective resistance usually varies from a minimum value of 2 or 3 ohms at the beginning of a discharge to 10 or more ohms near the end.

\section{EVALUATION OF ENERGY}

Another way of defining the effective resistance of the discharge circuit during one cycle is to say that it is that value of resistance which, when multiplied by the square of the instantaneous current, integrated over the cycle, gives the total energy expended during that cycle. Thus,

$$
W=R \int_{0}^{\frac{2 \pi}{\omega}} i^{2} d t
$$

If the damping factor be neglected in carrying out this integration, the result is

$$
W_{n}=R_{n} I_{n}^{2} / 2 f,
$$

where $R_{n}$ and $I_{n}$ are the effective resistance and crest current in the $n$th cycle, $f$ is the frequency, and $W_{n}$ is the energy expended in that cycle. The total energy expended in a train of $N$ oscillations is then

$$
W=\frac{1}{2 f} \sum_{n=1}^{N} I_{n}^{2} R_{n}
$$

This sum should be equal to the energy stored in the capacitor at the beginning of the discharge. The degree to which such equivalence is obtained is an indication of the accuracy with which $R$ has been determined.

\section{RESULTS}

\section{SPARK CHARACTERISTICS BY MEASUREMENT OF VOLTAGE ACROSS A KNOWN INDUCTANCE}

(a) CALIBRATION

Figure 6 is an oscillogram made with the standard discharge circuit, using the five-turn coil as inductance $L_{1}$. The capacitance $C$ was 200 
$\mu \mu \mathrm{f}$. The oscillograph was connected across the spark gap and the inductance $L_{1}$. The discharge voltage was applied to that pair of deflection plates which produced a horizontal deflection. A time scale was made by applying alternating voltage of $77.5-\mathrm{kc} / \mathrm{s}$ frequency to the other pair of plates, which produced a vertical deflection. The relatively low rate of rise of voltage across the spark gap is shown by the deflection of the beam to the right of the zero voltage line during about two cycles of the timing wave, until the point $a$ is reached. Here the gap breaks down, and the subsequent oscillations of voltage during the discharge, which can be more easily seen on the original oscillogram, are indicated in figure 6 by marking the deflection peaks.

In this oscillogram the true line of zero voltage is the line $x y$, rather than the heavy white line. This displacement of the zero line is due to a residual charge left on the capacitance voltage divider at the end of the preceding spark. (See appendix B.)

The position of the line $x y$ was determined from the turning points, using eq 12. It was found that the assumption of logarithmic or linear damping made no appreciable difference in the position of this line.

Using eq 7 and measurements from figure 6 , the frequency is found to be $10 \mathrm{Mc} / \mathrm{s}$, which agrees with the frequency computed from the circuit constants.

Amplitude measurements were made on the left side of figure 6, because several of the oscillations of low amplitude on the right side were poorly defined. These amplitudes are given in table 1 , column 2 . These are plotted and a smooth curve drawn through them (plot 1(a), fig. 10). The adjusted amplitudes, in column 3, are taken from this curve; and ratios of successive amplitudes (column 4), decrements (column 5) and resistance (column 6) are all based on these adjusted values. This results in a set of resistance values which vary more uniformly than if they were computed directly from the measured amplitudes.

TABLE 1.-Analysis of spark discharge from oscillogram of figure 6

$I_{n}=\frac{V_{n}}{\omega \mathrm{L}_{1}}=\frac{13.3 \times 180 \times \text { amplitude }}{2 \pi \times 10 \times 10^{6} \times 1.27 \times 10^{-0}}=30.1 \times$ amplitude.

$R_{n}=\frac{\delta_{n}}{\pi \omega C}=25.4 \delta_{n}$.

$W=\frac{45500}{2 \times 10 \times 10^{6}}=0.0023 \mathrm{j}$.

\begin{tabular}{|c|c|c|c|c|c|c|c|c|}
\hline Oscillation number & $\begin{array}{l}\text { Meas- } \\
\text { ured } \\
\text { ampli- } \\
\text { tude }\end{array}$ & $\begin{array}{l}\text { Ampli- } \\
\text { tude } \\
\text { from } \\
\text { plot 1 (a), } \\
\text { fig. } 10\end{array}$ & $\frac{I_{n}}{\frac{I_{n}}{I_{n+1}}}$ & $\begin{array}{l}\text { Decre- } \\
\text { ment }\end{array}$ & $\begin{array}{l}\text { Decre- } \\
\text { ment } \\
\text { from } \\
\text { plot } 1(\mathrm{~b}) \\
\text { fig. } 10\end{array}$ & $\begin{array}{l}\text { Effective } \\
\text { resist- } \\
\text { ance }\end{array}$ & $\begin{array}{c}\text { Crest } \\
\text { current }\end{array}$ & $I^{2} R$ \\
\hline $\begin{array}{l}1 \\
4 \\
4\end{array}$ & $\begin{array}{l}\mathrm{cm} \\
1.95 \\
1.80 \\
1.65 \\
1.50 \\
1.30\end{array}$ & $\begin{array}{l}\text { 1. } 95 \\
1.80 \\
1.65 \\
1.47 \\
1.30\end{array}$ & $\begin{array}{l}1.08 \\
1.09 \\
1.12 \\
1.13 \\
1.13\end{array}$ & $\begin{array}{r}0.08 \\
.09 \\
.11 \\
.12 \\
.12\end{array}$ & $\begin{array}{r}0.08 \\
.09 \\
.10 \\
.11 \\
.12\end{array}$ & $\begin{array}{l}2.0 \\
2.3 \\
2.5 \\
2.8 \\
3.0\end{array}$ & $\begin{array}{r}a \\
58 \\
54 \\
50 \\
44 \\
39\end{array}$ & $\begin{array}{l}\text { w } \\
6,700 \\
6,700 \\
6,200 \\
5,400 \\
4,600\end{array}$ \\
\hline $\begin{array}{l}6 \\
7 \\
8\end{array}$ & $\begin{array}{l}1.15 \\
1.05 \\
0.85 \\
.75 \\
.65\end{array}$ & $\begin{array}{l}1.15 \\
1.02 \\
0.88 \\
.76 \\
.65\end{array}$ & $\begin{array}{l}\text { 1. } 13 \\
1.16 \\
1.16 \\
1.17 \\
1.18\end{array}$ & $\begin{array}{l}.12 \\
.15 \\
.15 \\
.16 \\
.17\end{array}$ & $\begin{array}{l}.13 \\
.14 \\
.15 \\
.16 \\
.18\end{array}$ & $\begin{array}{l}3.3 \\
3.6 \\
3.8 \\
4.1 \\
4.6\end{array}$ & $\begin{array}{l}34 \\
30 \\
26 \\
23 \\
19\end{array}$ & $\begin{array}{l}3,800 \\
3,200 \\
2,600 \\
2,200 \\
1,700\end{array}$ \\
\hline 11,12 & $\begin{array}{l}.55 \\
.45 \\
.35\end{array}$ & $\begin{array}{l}.55 \\
.45 \\
.35\end{array}$ & $\begin{array}{l}\text { 1. } 22 \\
\text { 1. } 29\end{array}$ & $\begin{array}{l}.20 \\
.25\end{array}$ & $\begin{array}{l}.21 \\
.25 \\
.35\end{array}$ & $\begin{array}{l}5.3 \\
6.4 \\
8.9\end{array}$ & $\begin{array}{l}16 \\
13 \\
10\end{array}$ & $\begin{array}{r}1,400 \\
1,100 \\
900 \\
\end{array}$ \\
\hline Total & & & & & & & & 45,500 \\
\hline
\end{tabular}




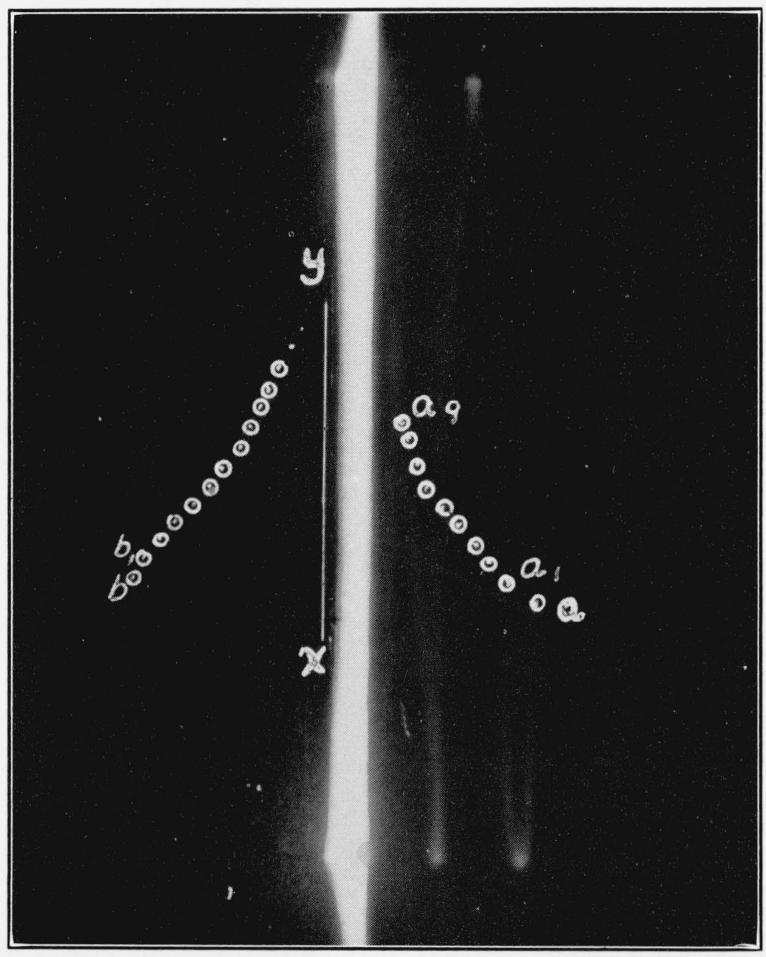

FIGURE 6.-Oscillogram of spark discharge, obtained for calibration of oscillograph for measurement of voltage across inductance. 


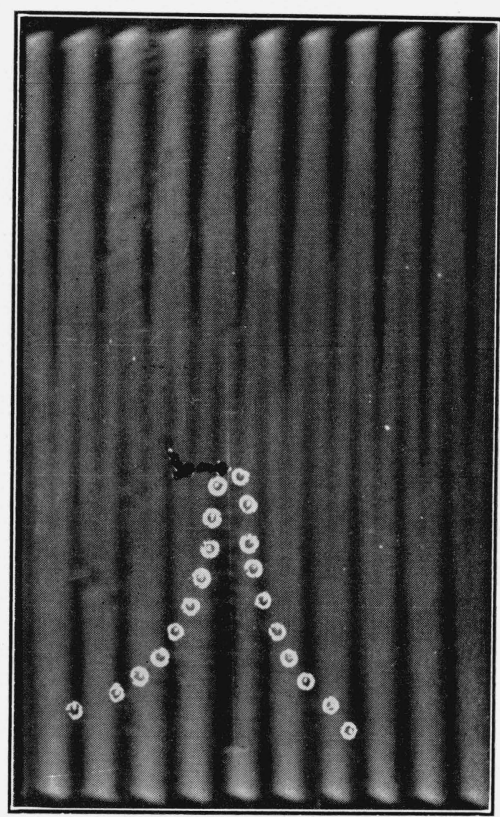

FIGURE 7.-Oscillogram of spark discharge in a typical ignition circuit, using the voltage drop across inductance to produce deflection.

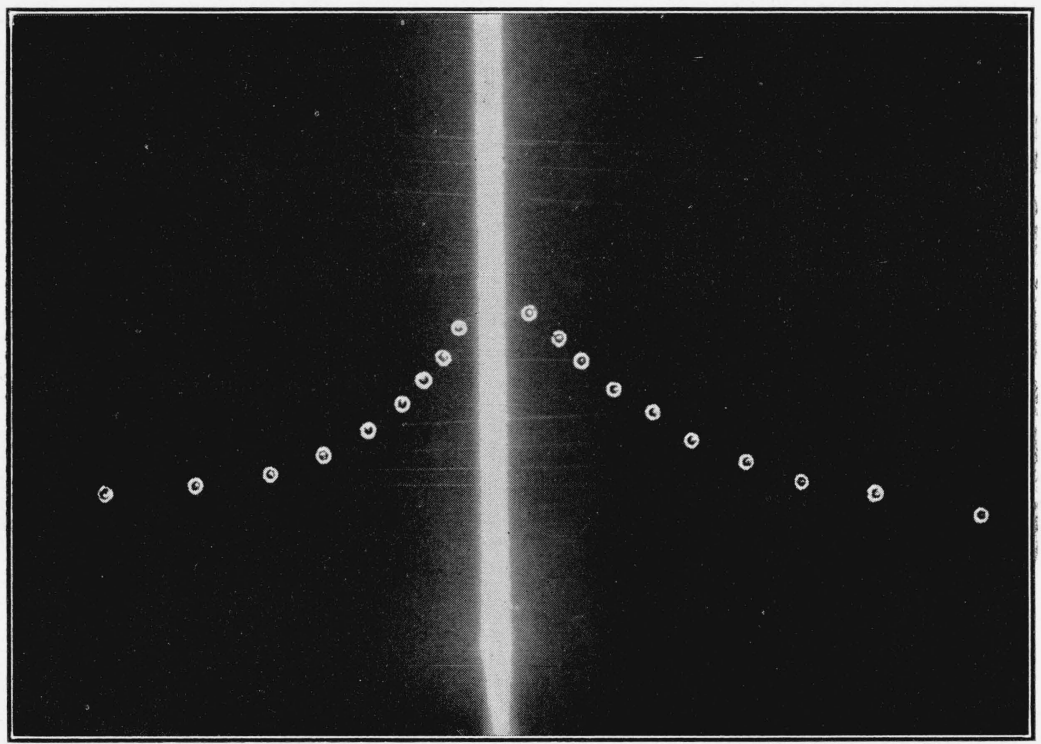

FIGURE 8.-Oscillogram of spark discharge in a typical ignition curcuit, using the magnetic field of the current to produce deflection. 
To calibrate the oscillograph circuit, or in other words to determine what correction must be applied to the measured voltage to obtain the true voltage, it is only necessary to compare the amplitude $a$ with the amplitude $a_{1}$, after multiplying the latter by the ratio which has been found to exist between successive amplitudes. From table 1, this ratio for the amplitudes $b$ and $b_{1}$ is 1.08 . The deflection at $a$ is $2.1 \mathrm{~cm} ; a_{1}$ is $1.9 \mathrm{~cm}$, and this multiplied by 1.08 gives $2.05 \mathrm{~cm}$. The difference, $0.05 \mathrm{~cm}$, is within the experimental error of measurement of the deflection, and therefore no correction is necessary.

As a check on the accuracy of the method the computations summarized in table 1 were made. The voltage across the gap is found by multiplying the deflection at $a$ by the deflection constant of the oscillograph, which is $180 \mathrm{v} / \mathrm{cm}$, and by the reduction factor $K$ of the voltage divider, which is 13.3. The breakdown voltage is therefore 5,000 v. Current maxima (table 1, column 8) are computed from eq 4. Finally, the average power during each cycle is computed (column 9). From this the total energy expended is found to be $0.0023 \mathrm{j}$, while the amount originally stored in the capacitor was $0.0025 \mathrm{j}$. These results are in sufficiently close agreement, especially when it is realized that a small amount of energy may still be left in the capacitor when the discharge ceases.

\section{(b) MEASUREMENTS ON TYPICAL IGNITION CIRCUIT}

Figure 7 is an oscillogram of a spark discharge through the longest lead (about $6 \mathrm{ft}$ ) of a shielded ignition harness, using the measuring circuit whose calibration is discussed above. One end of the lead was connected to the magneto and the other end to a spark plug. The spark plug was screwed into a bomb and the electrodes surrounded by an atmosphere of $\mathrm{CO}_{2}$ gas at $105-\mathrm{lb} / \mathrm{in} .{ }^{2}$ pressure. The $L_{1}$ inductor was connected in the discharge circuit on the grounded side of the spark plug, and the oscillations of voltage across this coil were superposed on the timing wave. The timing wave was spread out across the photographic film by using the varying magnetic field of 60-c current, this field deflecting the beam from left to right in figure 7 , at a rate of about $3.6 \times 10^{4} \mathrm{~cm} / \mathrm{s}$.

The frequency in this discharge was $5.9 \mathrm{Mc} / \mathrm{s}$. The capacitance, measured with current of 2,000-c frequency, was $200 \mu \mu$. The corresponding inductance is therefore $L=1 / \omega^{2} C=3.6 \mu \mathrm{h}$.

Since both positive and negative turning points are visible the double amplitudes were measured, and are tabulated in table 2, column 2. The smooth curve through the plotted turning points (plot 2(a), fig. 10) gives the adjusted amplitudes in column 3, and from these are computed the decrements shown in plot 2(b). The adjusted decrement for each cycle is obtained from the smooth curve through these points, and from these the effective resistance shown in column 8 are obtained. Both positive and negative maximum currents were measured, and the total energy obtained as before. This is $0.0135 \mathrm{j}$.

The breakdown voltage of the gap may be computed from the total energy. The agreement, for the previous case, between the energy computed from the oscillogram and the initial energy in the capacitor indicates the reliability of this method. From $C V^{2} / 2=0.0135 \mathrm{j}$, the voltage $V=11,600 \mathrm{v}$. 
TABLE 2.-Analysis of spark discharge from oscillogram of figure 7

$$
\begin{aligned}
& I_{n}=\frac{V_{n}}{\omega L_{1}}=\frac{13.3 \times 180 \times \text { amplitude }}{2 \pi \times 5.9 \times 10^{6} \times 1.15 \times 10^{-6}}=56.2 \times \text { amplitude. } \\
& R_{n}=\frac{\delta_{n}}{\pi \omega C}=42.9 \delta_{n} . \\
& W=\frac{159600}{2 \times 5.9 \times 10^{6}}=0.0135 \mathrm{j} .
\end{aligned}
$$

\begin{tabular}{|c|c|c|c|c|c|c|c|c|c|c|c|}
\hline 1 & 2 & 3 & 4 & 5 & 6 & 7 & & 8 & & 9 & 10 \\
\hline \multirow{2}{*}{$\begin{array}{l}\text { Oscillation } \\
\text { number }\end{array}$} & \multirow{2}{*}{$\begin{array}{l}\text { Meas- } \\
\text { ured } \\
\text { double } \\
\text { ampli- } \\
\text { tude }\end{array}$} & \multirow{2}{*}{$\begin{array}{l}\text { Double } \\
\text { ampli- } \\
\text { tude } \\
\text { from } \\
\text { plot } \\
2 \text { (a), } \\
\text { fig. } 10\end{array}$} & \multirow{2}{*}{$\begin{array}{c}\text { Ratio, } \\
\frac{I_{n}}{I_{n+1}}\end{array}$} & \multirow[b]{2}{*}{$\begin{array}{l}\text { Decre- } \\
\text { ment }\end{array}$} & \multirow{2}{*}{$\begin{array}{l}\text { Decre- } \\
\text { ment } \\
\text { from } \\
\text { plot } \\
2 \text { (b), } \\
\text { fig. } 10\end{array}$} & \multirow{2}{*}{$\begin{array}{l}\text { Effec- } \\
\text { tive } \\
\text { resist- } \\
\text { ance }\end{array}$} & \multicolumn{2}{|c|}{ Amplitude } & \multicolumn{2}{|c|}{ Crest current } & \multirow[b]{2}{*}{$I^{2} R$} \\
\hline & & & & & & & Left & Right & Left & Right & \\
\hline & $\begin{array}{l}\mathrm{cm} \\
2.80 \\
2.20 \\
1.70 \\
1.30 \\
1.00\end{array}$ & $\begin{array}{l}2.80 \\
2.20 \\
1.70 \\
1.30 \\
1.00\end{array}$ & $\begin{array}{l}\text { 1. } 27 \\
1.29 \\
1.31 \\
1.30 \\
1.33\end{array}$ & $\begin{array}{l}0.24 \\
.26 \\
.27 \\
.26 \\
.29\end{array}$ & $\begin{array}{r}0.234 \\
.248 \\
.260 \\
.272 \\
.286\end{array}$ & $\begin{array}{c}\text { ohms } \\
10.0 \\
10.6 \\
11.2 \\
11.6 \\
12.2\end{array}$ & $\begin{array}{l}\mathrm{cm} \\
1.31 \\
1.03 \\
0.79 \\
.61 \\
.46\end{array}$ & $\begin{array}{l}\text { cm } \\
1.49 \\
1.17 \\
.91 \\
.69 \\
.54\end{array}$ & $\begin{array}{r}a m p \\
73 \\
58 \\
44 \\
34 \\
26\end{array}$ & $\begin{array}{r}a m p \\
84 \\
65 \\
51 \\
38 \\
30\end{array}$ & $\begin{array}{l}\text { W } \\
61,800 \\
40,000 \\
22,000 \\
15,000 \\
9,600\end{array}$ \\
\hline $\begin{array}{l}6 \\
7 \\
8\end{array}$ & $\begin{array}{l}0.75 \\
.55 \\
.40 \\
.30\end{array}$ & $\begin{array}{l}0.75 \\
.55 \\
.40 \\
.30\end{array}$ & $\begin{array}{l}1.36 \\
1.38 \\
1.33\end{array}$ & $\begin{array}{l}.31 \\
.32 \\
.29\end{array}$ & $\begin{array}{l}.298 \\
.312 \\
.324 \\
.336\end{array}$ & $\begin{array}{l}12.8 \\
13.4 \\
13.9 \\
14.4\end{array}$ & $\begin{array}{l}.35 \\
.25 \\
.18 \\
.14\end{array}$ & $\begin{array}{l}.40 \\
.30 \\
.22 \\
.16\end{array}$ & $\begin{array}{r}20 \\
14 \\
10 \\
8\end{array}$ & $\begin{array}{r}22 \\
17 \\
12 \\
9\end{array}$ & $\begin{array}{r}5,600 \\
2,900 \\
1,400 \\
800\end{array}$ \\
\hline Total. & & & & & & & & & & & 159,600 \\
\hline
\end{tabular}

\section{SPARK CHARACTERISTICS BY MEASUREMENT OF MAGNETIC} DEFLECTION

(a) MEASUREMENTS ON TYPICAL IGNITION CIRCUIT

The circuit on which measurements were made by the measurement of voltage across inductance was also used as an example in the method of magnetic deflection. Suitable deflection coils were made and placed in such a position adjacent to the deflection tube that the discharge current produced the oscillogram shown in figure 8 . The frequency is in this case $6.6 \mathrm{Mc} / \mathrm{s}$. The deflection constant for the coils in this position was subsequently found to be $15.5 \mathrm{amp} / \mathrm{cm}$., so that the crest current is approximately $84 \mathrm{amp}$. Table 3 with plot 3 Figure 11 gives the results of measures on this oscillogram.

\section{(b) CALIBRATION}

The standard discharge circuit was used to determine the deflection constant of the oscillograph with the deflection coils in the position they occupied during measurements on the typical ignition circuit. The three-turn coil was used in series with the deflection coils, and the total inductance of the circuit was measured by the method described in section IV, 1 (b), page 407 . This was $1.95 \mu \mathrm{h}$. The capacitance $C$ was $200 \mu \mu \mathrm{f}$. The current in the standard discharge circuit is shown in the oscillogram of figure 9 . The frequency was $7.9 \mathrm{Mc} / \mathrm{s}$. 


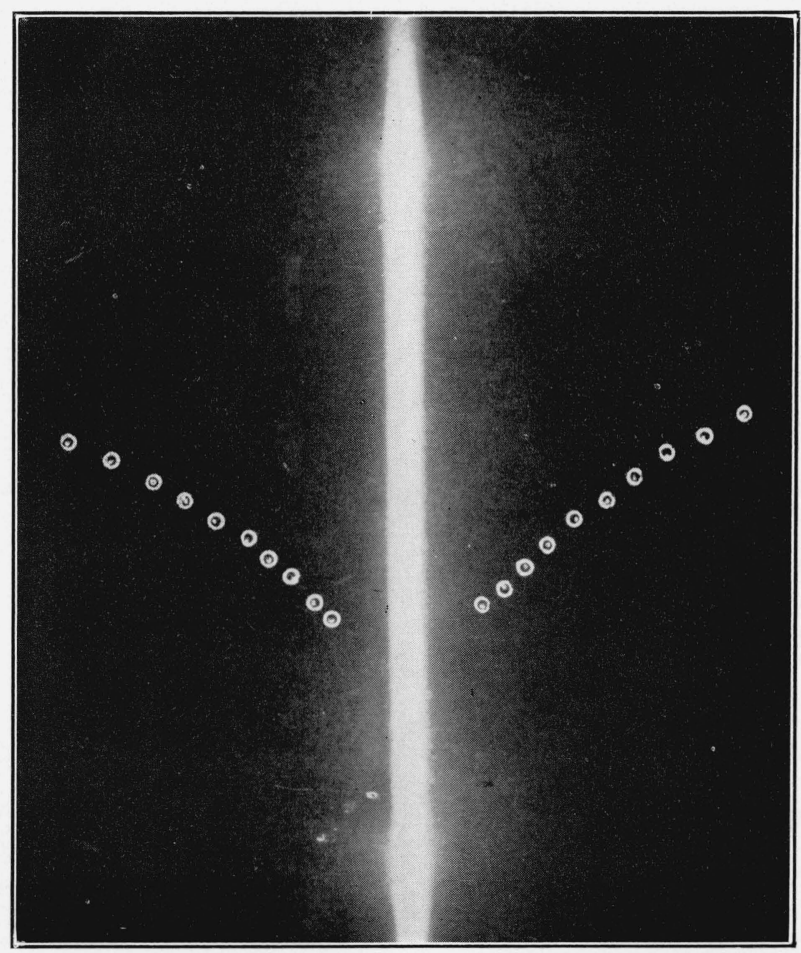

FigURE 9.-Oscillogram of spark discharge, obtained for calibration of the oscillograph for measurement of current by magnetic deflection. 
TABLE 3.-Analysis of spark discharge from oscillogram of figure 8

$I_{n}=15.5 \times$ amplitude.

$W=\frac{158900}{2 \times 6.6 \times 10^{6}}=0.0120 \mathrm{j}$.

\begin{tabular}{|c|c|c|c|c|c|c|c|c|c|}
\hline 1 & 2 & 3 & 4 & 5 & 6 & 7 & 8 & 9 & 10 \\
\hline $\begin{array}{l}\text { Oscillation } \\
\text { number }\end{array}$ & $\begin{array}{l}\text { Meas- } \\
\text { nred } \\
\text { double } \\
\text { ampli- } \\
\text { tude }\end{array}$ & $\begin{array}{l}\text { Double } \\
\text { ampli- } \\
\text { tude } \\
\text { from } \\
\text { plot } 3 \text { (a), } \\
\text { fig. } 11\end{array}$ & $\begin{array}{l}\text { Ratio, } \\
\frac{I_{n}+I^{\prime}{ }_{n}}{I_{n+1}+I^{\prime}{ }_{n+1}}\end{array}$ & $\begin{array}{l}\text { Decre- } \\
\text { ment }\end{array}$ & Ampli- & $\begin{array}{l}\text { Resist- } \\
\text { ance }\end{array}$ & $\begin{array}{l}\text { Resist- } \\
\text { ance, } \\
\text { average } \\
\text { for half- } \\
\text { cycle } \\
\text { from } \\
\text { plot 3(b) } \\
\text { fig. } 11\end{array}$ & $\begin{array}{l}\text { Crest } \\
\text { current }\end{array}$ & $I^{2} R$ \\
\hline$\ldots$ & $\begin{array}{c}\mathrm{cm} \\
10.8 \\
8.4 \\
6.6 \\
5.1 \\
4.0\end{array}$ & $\begin{array}{r}10.80 \\
8.50 \\
6.60 \\
5.10 \\
4.05\end{array}$ & $\begin{array}{l}\text { 1. } 27 \\
\text { 1. } 29 \\
\text { 1. } 29 \\
\text { 1. } 26 \\
\text { 1. } 29\end{array}$ & $\begin{array}{r}0.24 \\
.25 \\
.25 \\
.23 \\
.25\end{array}$ & $\begin{array}{c}\mathrm{cm} \\
5.4 \\
4.2 \\
3.2 \\
2.4 \\
1.9\end{array}$ & $\begin{array}{r}\text { Ohms } \\
9.2 \\
9.8 \\
9.8 \\
8.9 \\
9.8\end{array}$ & $\begin{array}{r}\text { Ohms } \\
9.2 \\
9.2 \\
9.2 \\
9.3 \\
9.6\end{array}$ & $\begin{array}{r}\text { amp } \\
84 \\
65 \\
50 \\
37 \\
29\end{array}$ & $\begin{array}{c}\mathrm{w} \\
65,000 \\
39,000 \\
23,000 \\
12,800 \\
8,100\end{array}$ \\
\hline 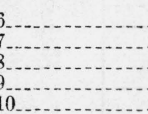 & $\begin{array}{l}3.1 \\
2.3 \\
1.7 \\
1.2 \\
0.8\end{array}$ & $\begin{array}{l}3.15 \\
2.40 \\
1.70 \\
1.20 \\
0.80\end{array}$ & $\begin{array}{l}\text { 1. } 31 \\
\text { 1. } 41 \\
1.42 \\
1.50\end{array}$ & $\begin{array}{l}.27 \\
.34 \\
.35 \\
.40\end{array}$ & $\begin{array}{r}1.4 \\
1.0 \\
0.8 \\
.5 \\
.3\end{array}$ & $\begin{array}{l}10.4 \\
13.2 \\
13.5 \\
15.6\end{array}$ & $\begin{array}{l}10.4 \\
11.4 \\
12.8 \\
14.6 \\
16.6\end{array}$ & $\begin{array}{r}25 \\
16 \\
12 \\
8 \\
5\end{array}$ & $\begin{array}{r}5,000 \\
2,900 \\
1,800 \\
900 \\
400\end{array}$ \\
\hline Total_ & & & & & & & & & 158,900 \\
\hline
\end{tabular}

The coils were then removed and by measuring the voltage across $L_{1}$ in another discharge it was found that the crest current was $53 \mathrm{amp}$, which corresponds to the maximum deflection of $3.4 \mathrm{~cm}$ in figure 9 . The deflection constant is therefore $53 / 3.4=15.5 \mathrm{amp} / \mathrm{cm}$. Table 4 gives the results of measurements made on the oscillogram of figure 9 , for which actual measurements are shown on plot 4, figure 11 .

TABLE 4.-Analysis of spark discharge from oscillogram of figure 9

$I_{n}=15.5 \times$ amplitude.

$W=\frac{47200}{2 \times 7.9 \times 10^{6}}=0.0024 \mathrm{j}$.

\begin{tabular}{|c|c|c|c|c|c|c|c|c|c|}
\hline 1 & 2 & 3 & 4 & 5 & 6 & 7 & 8 & 9 & 10 \\
\hline $\begin{array}{l}\text { Oscillation } \\
\text { number }\end{array}$ & $\begin{array}{l}\text { Meas- } \\
\text { ured } \\
\text { double } \\
\text { ampli- } \\
\text { tude }\end{array}$ & $\begin{array}{l}\text { Double } \\
\text { ampli- } \\
\text { tude } \\
\text { from } \\
\text { plot 4(a), } \\
\text { fig. 11 }\end{array}$ & $\begin{array}{c}\text { Ratio, } \\
\frac{I_{n}+I_{n}^{\prime}}{I_{n+1}+I_{n+1}^{\prime}}\end{array}$ & $\begin{array}{l}\text { Decre- } \\
\text { ment }\end{array}$ & Ampli- & $\begin{array}{l}\text { Resist- } \\
\text { ance }\end{array}$ & $\begin{array}{l}\text { Resist- } \\
\text { ance, } \\
\text { average } \\
\text { for half- } \\
\text { cycle, } \\
\text { fromi } \\
\text { plot } 4 \text { (b), } \\
\text { fig. } 11\end{array}$ & $\begin{array}{c}\text { Crest } \\
\text { current }\end{array}$ & $I^{2} R$ \\
\hline & $\begin{array}{r}\mathrm{cm} \\
6.80 \\
6.00 \\
5.20 \\
4.50 \\
3.95\end{array}$ & $\begin{array}{l}6.80 \\
6.02 \\
5.26 \\
4.53 \\
3.90\end{array}$ & $\begin{array}{l}1.13 \\
1.14 \\
1.16 \\
1.16 \\
1.18\end{array}$ & $\begin{array}{l}0.12 \\
.13 \\
.15 \\
.15 \\
.17\end{array}$ & \begin{tabular}{c|}
$\mathrm{cm}$ \\
3.4 \\
3.0 \\
2.6 \\
2.3 \\
2.0
\end{tabular} & $\begin{array}{r}\text { Ohms } \\
3.8 \\
4.0 \\
4.6 \\
4.6 \\
5.1\end{array}$ & $\begin{array}{r}\text { Ohms } \\
3.7 \\
3.9 \\
4.2 \\
4.5 \\
4.9\end{array}$ & $\begin{array}{r}a m p \\
53 \\
46 \\
40 \\
36 \\
31\end{array}$ & $\begin{array}{c}\mathrm{w} \\
10,400 \\
8,300 \\
6,700 \\
5,800 \\
4,700\end{array}$ \\
\hline 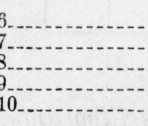 & $\begin{array}{l}3.30 \\
2.80 \\
2.30 \\
1.90 \\
1.50\end{array}$ & $\begin{array}{l}3.30 \\
2.81 \\
2.33 \\
1.87 \\
1.50\end{array}$ & $\begin{array}{l}1.17 \\
1.21 \\
1.24 \\
1.25\end{array}$ & $\begin{array}{l}.16 \\
.19 \\
.22 \\
.22\end{array}$ & $\begin{array}{l}1.7 \\
1.4 \\
1.2 \\
1.0 \\
0.8\end{array}$ & $\begin{array}{l}4.8 \\
5.9 \\
6.6 \\
6.9\end{array}$ & $\begin{array}{l}5.3 \\
5.7 \\
6.2 \\
6.6 \\
7.1\end{array}$ & $\begin{array}{l}26 \\
22 \\
19 \\
16 \\
12\end{array}$ & $\begin{array}{l}3,600 \\
2,800 \\
2,200 \\
1,700 \\
1,000\end{array}$ \\
\hline Total. & & & & & & & & & 47,200 \\
\hline
\end{tabular}




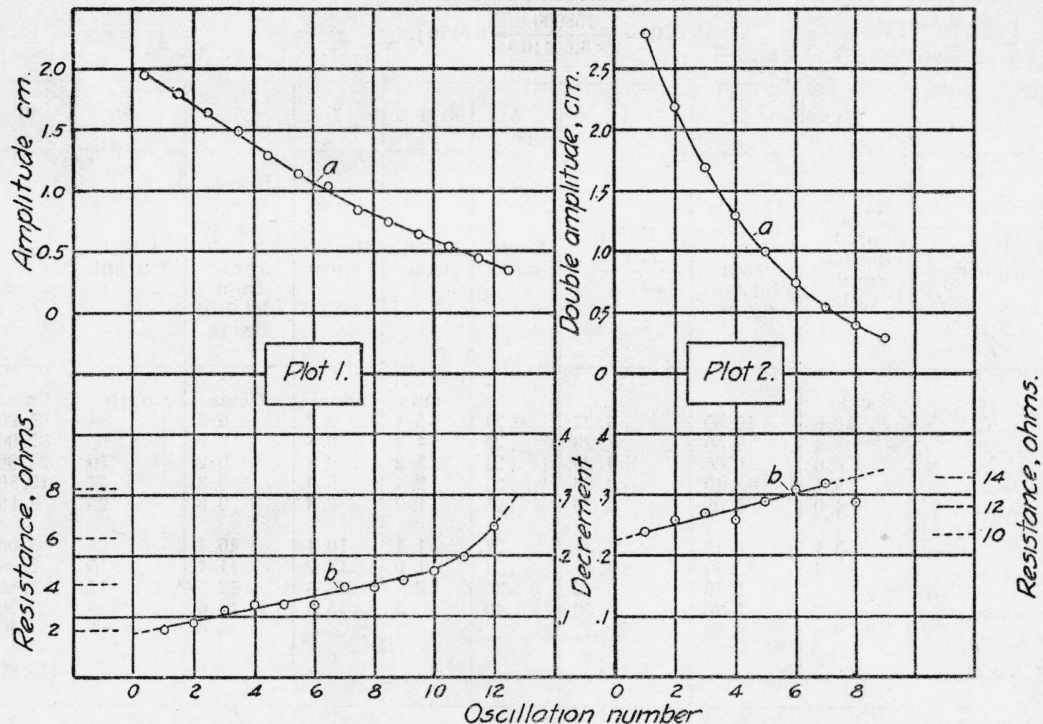

Figure 10.-Measurements of amplitude, decrement, and resistance, from oscillograms shown in figures 6 and $\%$.

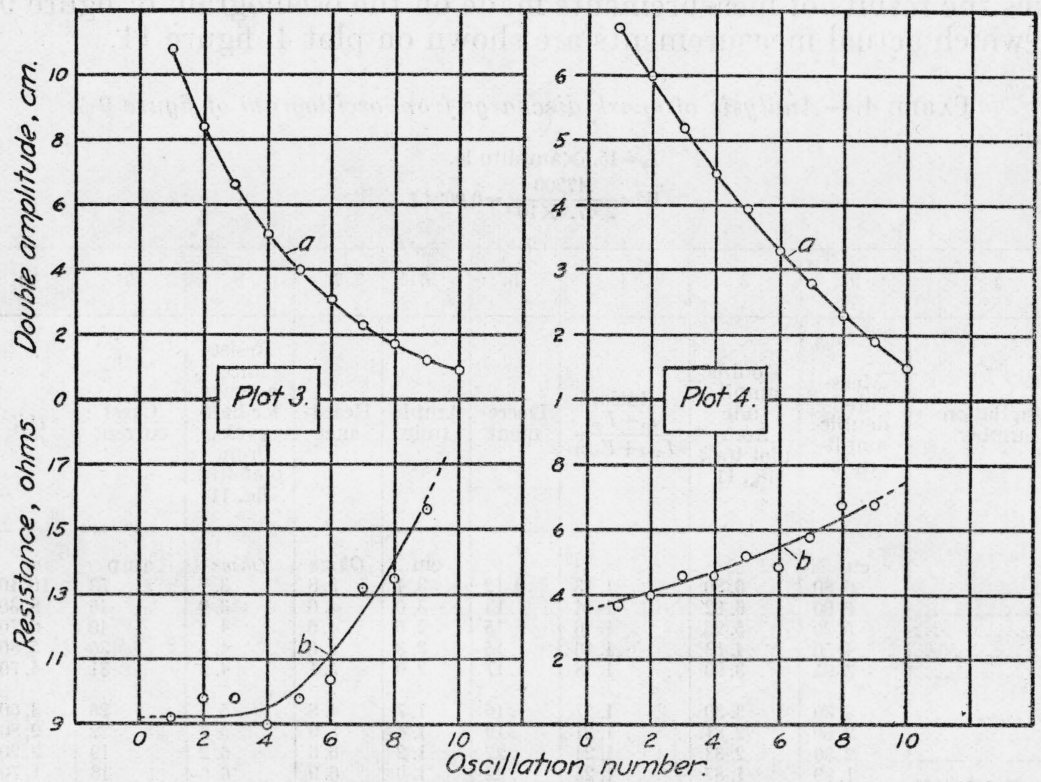

FIGURE 11,-Measurements of amplitude, decrement, and resistance from oscillograms shown in figures 8 and. 9. 


\section{DISCUSSION OF RESULTS}

The sources of accidental error in making current or voltage measurements lie chiefly in the measurements of deflection and in determining the sensitivity of the oscillograph. The uncertainty of the values given in the tables for voltage and current from measurements made on the oscillograms is difficult to determine, especially when the cathode beam is deflected so rapidly that no well-defined trace is left on the film.

It is possible to correct the measured values of current for the presence of the measuring circuit. Thus, in the case of the circuit for which measurements are given in table 2, the omission of the $L_{1}$ inductor would deduct $1.15 \mu \mathrm{h}$ from the total inductance of the circuit, leaving $2.45 \mu \mathrm{h}$. The crest current of the discharge would be approximately 20 percent greater than that measured. The total energy remains the same.

It will be noted that energy is being dissipated at the rate of $60 \mathrm{kw}$ at $6.5 \mathrm{Mc} / \mathrm{s}$. It is also probable that there are present in the discharge, especially at its beginning, still more powerful transient phenomena, of too high speed to be recorded by the oscillograph. In particular the discharge of the capacitance of the spark plug through the low inductance of the spindle shank may give rise to exceedingly high currents of very short duration. For example, the inductance of the spindle shank of a typical mica spark plug computed from its dimensions is about $0.04 \mu \mathrm{h}$, and the measured capacitance ranges from $15 \mu \mu \mathrm{f}$ for unshielded plugs to $50 \mu \mu \mathrm{f}$ for shielded plugs. Using these values, the natural freouency of the discharge of the plug itself would range from 100 to $200 \mathrm{Mc} / \mathrm{s}$ (wave length 3 to $1.5 \mathrm{~m}$ ), and the crest currents for an initial voltage of 5,000 v would range from 100 to $175 \mathrm{amp}$. Radiation at these frequencies, as well as at the lower frequency, say 6 $\mathrm{Mc} / \mathrm{s}$ (wave length $50 \mathrm{~m}$ ), of the main capacitive part of the ignition circuit, might cause interference with reception in aircraft or automobile radio receivers.

Not all of the energy available in the secondary winding of the magneto or other source of high voltage is stored in the first charge in the capacitance of the circuit. At the end of the capacitive component of the discharge the energy remaining in the winding, or part of it, may appear as an inductive component, in which a unidirectional current of a small fraction of an ampere flows through the circuit for a relatively long time, compared with the time elapsed during the capacitive component. This inductive component is not observable with the high-voltage oscillograph, as the sensitivity of this type of oscillograph is too low. It has, however, been observed with the vibrating-string type of oscillograph [3], and with the low-voltage, hot-cathode type of cathode-ray oscillograph [4].

The "spark" occurring in the secondary circuit of a spark generator on interrupting the primary current usually consists of a number of separate discharges, each of which may consist of a capacitive and an inductive component. In each discharge the decay of the current in the inductive component, if such a component is present, is followed by the rapid rise of resistance of the gap, whereupon the capacitance is again charged to such voltage that the discharge is repeated. The spark ends when there is no longer sufficient energy in the secondary winding to charge the capacitance to the breakdown voltage. 


\section{REFERENCES}

[1] BS J. Research 9, 81 (1932) RP460.

[2] Cir. NBS 74.

[3] Ntl. Advisory Comm. Aeron. Rept. 58 (1920).

[4] Proc. Phys. Soc. (London) 45, 288 (1933).

[5] Fleming, Principles of Electric Wave Telegraphy and Telephony, 3d ed. (Longmans \& Co., London, 1916).

[6] BS Sci. Pap. 17, 407 (1922) S424.

\section{APPENDIX A}

\section{DERIVATION OF EXPRESSION FOR VOLTAGE ACROSS CAPACITANCE OF OSCILLOGRAPH CIRCUIT}

In measuring the voltage across a portion of the inductance of the discharge circuit, the oscillograph and connecting leads constitute a circuit coupled inductively with the discharge circuit. The voltage across the deflection plates can be found by mathematical methods usually applied to such circuits. Consider the closed circuit $L_{1} L^{\prime} C^{\prime} R^{\prime}$ of figure 1. If, as has been assumed, the discharge itself is not appreciably affected by the presence of the measuring circuit, the electromotive force introduced into this circuit in a spark discharge is given by eq 2, viz:

$$
v_{L_{1}}=\frac{V_{\mathrm{o}} L_{1}}{\omega L} \sqrt{\alpha^{2}+\omega^{2}} e^{-\alpha t} \cos (\omega t+\theta)
$$

Applying Kirchhoff's law to this circuit, the resulting equation is

$$
\left(L_{1}+L^{\prime}\right) \frac{d i_{2}}{d t}+R^{\prime} i_{2}+v_{C}=v_{L 1}
$$

where $i_{2}$ is the instantaneous current in the oscillograph circuit, and $v_{\mathrm{C}}$ is the instantaneous voltage across the capacitance in this circuit.

Since

$$
i_{2}=C^{\prime} \frac{d v_{C}}{d t}
$$

eq $2 a$ may be written

$$
\begin{gathered}
\frac{d^{2} v_{C}}{d t^{2}}+\frac{R^{\prime}}{\left(L_{1}+L^{\prime}\right)} \frac{d v_{C}}{d t}+\frac{v_{C}}{\left(L_{1}+L^{\prime}\right) C^{\prime}}= \\
\frac{V_{0} L_{1}}{\omega L\left(L_{1}+L^{\prime}\right) C^{\prime}} \sqrt{\alpha^{2}+\omega^{2}} e^{-\alpha t} \cos (\omega t+\theta)
\end{gathered}
$$

Writing $\lambda=R^{\prime} / 2\left(L_{1}+L^{\prime}\right)$ and $\beta^{2}=1 / C^{\prime}\left(L_{1}+L^{\prime}\right)$, this becomes

$$
\frac{d^{2} v_{C}}{d t^{2}}+2 \lambda \frac{d v_{C}}{d t}+\beta^{2} v_{C}=\frac{\beta^{2} V_{0} L_{1}}{\omega L} \sqrt{\alpha^{2}+\omega^{2}} e^{-\alpha t} \cos (\omega t+\theta)
$$

The general solution of this equation is the sum of a particular integral and a complementary function. The latter is of the form $\left(A e^{-m_{1} t}\right.$ $\left.+B e^{-m_{2} t}\right)$, where $m_{1}$ and $m_{2}$ are the roots of the auxiliary equation

$$
m^{2}+2 \lambda m+\beta^{2}=0
$$


The particular integral may be found by the usual method of factorizing the left-hand side of eq 5a and finding the integrating factors of the resulting first-order equations. The complete solution is

$$
\begin{aligned}
v_{C} & =\frac{V_{0} L_{1}}{P \omega L} \sqrt{\alpha^{2}+\omega^{2}} e^{-\alpha t} \cos (\omega t+\theta+\psi) \\
& +A_{1} e^{-\left(\lambda-\sqrt{\left.\lambda^{2}-\beta^{2}\right) t}\right.}+A_{2} e^{-\left(\lambda+\sqrt{\left.\lambda^{2}-\beta^{2}\right) t}\right.}
\end{aligned}
$$

Here $\lambda$ and $\beta$ have the meanings given above,

$$
\begin{gathered}
\beta \psi=\tan ^{-1} 2 \omega(\alpha-\lambda) /\left(\alpha^{2}+\beta^{2}-2 \alpha \lambda-\omega^{2}\right), \text { and } \\
P^{2}=1+\frac{2\left(\alpha^{2}-2 \alpha \lambda-\omega^{2}\right)}{\beta^{2}}+\frac{4 \lambda}{\beta^{4}}(\lambda-\alpha)\left(\alpha^{2}+\omega^{2}\right)+\frac{\left(\lambda^{2}+\omega^{2}\right)^{2}}{\beta^{4}}
\end{gathered}
$$

The integration constants $A_{1}$ and $A_{2}$ may be determined, if desired, from the initial conditions.

The first term on the right-hand side of the equation represents a forced oscillation in the measuring circuit, and it is this quantity which is to be measured. The second and third terms represent parasitic transients, and it is desirable that these be damped out very quickly. To do this, $\lambda$ should be made large compared with $\beta$, by including resistance in the oscillograph circuit. If $\beta>\lambda$ the transients will be oscillatory rather than aperiodic, and eq $7 \mathrm{a}$ then takes the form which represents two superimposed oscillations in the measuring circuit, well known in the theory of spark telegraphy and the theory of the induction coil $[5,6]$.

It is desirable that $P$ in eq 7 a be approximately equal to unity and that the angle $\psi$ be small, but the experimental limitations in the choice of $C^{\prime}$ and $L^{\prime}$ may sometimes mean that these desiderata cannot be obtained.

The correction factor to be applied to the observed voltage $v_{C}$ across the capacitance of the oscillograph circuit to find the voltage $v_{L_{1}}$ across $L_{1}$ is obtained by comparing the maximum voltage $V_{n}$ of the $n$th cycle derived from eq 1a, with $\left(V_{c}\right)_{n}$ derived from eq $7 \mathrm{a}$.

Thus

and

$$
V_{n}=\frac{V_{0} L_{1}}{\omega L} \sqrt{\alpha^{2}+\omega^{2}} e^{-\frac{\alpha}{\omega}(n \pi-\theta)}
$$

$$
\left(V_{C}\right)_{n}=\frac{V_{0} L_{1}}{P \omega L} \sqrt{\alpha^{2}+\omega^{2}} e^{-\frac{\alpha}{\omega}(n \pi-\theta-\psi)}
$$

assuming that the second and third terms on the right-hand side of eq 7a have become negligibly small.

Dividing eq $8 \mathrm{a}$ by eq $9 \mathrm{a}$,

$$
Q=\frac{V_{n}}{\left(V_{C}\right)_{n}}=P e^{-\frac{\alpha \phi}{\omega}}
$$

The quantity $Q$ is found experimentally by method described in section IV, 2, page 407. 


\section{APPENDIX B}

\section{DISPLACEMENT OF LINE OF ZERO VOLTAGE ON AN OSCILLOGRAM}

It sometimes occurs, as in figure 6 , that when the voltage being measured becomes zero the cathode beam of the oscillograph remains deflected away from its position for zero voltage on the deflection plates. This is due to the action of the capacitance voltage divider. It commonly occurs when recurrent voltage impulses are applied to the oscillograph, between which impulses the voltage is constant or

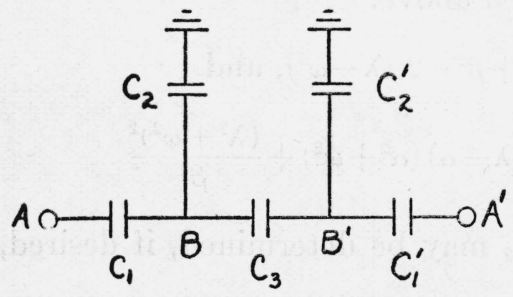

Figure 12.-Schematic diagram capacitance voltage divider. decays slowly, so that a charge remains on the high-tension circuit at the beginning of the next discharge.

Figure 12 shows the divider circuit, with $C_{3}$ representing the deflection plates of the oscillograph. Suppose a constant potential $\bar{V}_{A}$ is applied to $A$ until leakage reduces the potential at $B$ and $B^{\prime}$ to zero. $A^{\prime}$ is of assumed to be at zero potential. Since $\bar{V}_{B}=\bar{V}_{B}=0$, the cathode beam is not deflected. The charge which has leaked onto $B$ is $\bar{V}_{A} C_{1}$. If the voltages at $A$ and $A^{\prime}$ are suddenly changed to values $V_{A}$ and $V^{\prime}{ }_{A}$, respectively, the potentials of conductors $B$ and $B^{\prime}$ take corresponding values $V_{B}$ and $V_{B}^{\prime}$. Before appreciable leakage has taken place the total charge on $B$ is

$$
-\bar{V}_{A} C_{1}=\left(V_{B}-V_{A}\right) C_{1}+\left(V_{B}-V_{B}^{\prime}\right) C_{3}+V_{B} C_{2}
$$

Since the charge on $B^{\prime}$ remains zero

$$
0=\left(V_{B}^{\prime}-V_{B}\right) C_{3}+\left(V_{B}^{\prime}-V_{A}^{\prime}\right) C_{1}^{\prime}+V_{B}^{\prime} C_{2}^{\prime}
$$

Solving eq $1 \mathrm{~b}$ for $V_{A}$,

$$
V_{A}=V_{B}\left(1+\frac{C_{2}}{C_{1}}+\frac{C_{3}}{C_{1}}\right)-V_{B} \frac{C_{3}}{C_{1}}+\bar{V}_{A}
$$

In a similar manner $V^{\prime}$ is obtained from eq $2 \mathrm{~b}$,

$$
V_{A}^{\prime}=V_{B}^{\prime}\left(1+\frac{C_{2}^{\prime}}{C^{\prime}{ }_{1}}+\frac{C_{3}}{C^{\prime}{ }_{1}}\right)-V_{B} \frac{C_{3}}{C^{\prime}{ }_{1}}
$$

Subtracting eq $4 \mathrm{~b}$ from eq $3 \mathrm{~b}$ and putting $C_{2} / C_{1}=C^{\prime}{ }_{2} / C^{\prime}{ }_{1}$, which is a necessary operating condition for the voltage divider [1], and

the result is

$$
K=1+\frac{C_{2}}{C_{1}}+C_{3}\left(\frac{1}{C_{1}}+\frac{1}{C^{\prime}}\right) .
$$

$$
V_{A}-V_{A}^{\prime}=\left(V_{B}-V_{B}^{\prime}\right) K+\bar{V}_{A}, \text { or } V_{B}-V_{B}^{\prime}=\frac{V_{A}-V_{A}^{\prime}}{K}-\frac{\bar{V}_{A}}{K}
$$


The presence of the term $\bar{V}_{A} / K$ shows that a deflection proportional to this quantity is added to the deflection in one direction and subtracted in the opposite direction. This is equivalent to a displacement of the zero line in an oscillogram of alternating voltage. It can be prevented by reducing $\bar{V}_{A}$ to zero in the interval between sparks, either by means of a shunting resistance of the proper value or by momentarily grounding the circuit.

Washington, July 23, 1937. 